\title{
Simplified Shear Solution for Determination of the Shear Stress Distribution in a Composite Panel from the Applied Shear Resultant
}

The "simplified shear solution" method is presented for approximating the through-thickness shear stress distribution within a composite laminate or panel based on laminated beam theory. The method does not consider the solution of a particular boundary value problem; rather it requires only knowledge of the global shear loading, geometry, and material properties of the laminate or panel. It is thus analogous to lamination theory in that ply level stresses can be efficiently determined from global load resultants (as determined, for instance, by finite element analysis) at a given location in a structure and used to evaluate the margin of safety on a ply by ply basis. The simplified shear solution stress distribution is zero at free surfaces, continuous at ply boundaries, and integrates to the applied shear load. Comparisons to existing theories are made for a variety of laminates, and design examples are provided illustrating the use of the method for determining through-thickness shear stress margins in several types of composite panels and in the context of a finite element structural analysis. 


\title{
Simplified Shear Solution for Determination of the Shear Stress Distribution in a Composite Panel from the Applied Shear Resultant
}

\author{
Brett A. Bednarcyk \\ NASA Glenn Research Center, Cleveland, $\mathrm{OH}$ \\ Jacob Aboudi \\ Tel Aviv University, Ramat-Aviv, Israel \\ Phillip W. Yarrington and Craig S. Collier \\ Collier Research Corp., Hampton, VA \\ Acknowledgement: NASA Fundamental Aeronautics Integrated Vehicle Health \\ Management NRA 06-IVHM-06-0049
}




\section{Outline}

- Background

- Problem Definition

- Method Formulation

- Results

- Verification

- Design 


\section{HyperSizer automated structural sizing software optimizes composite panels based on FEA loads}

- HyperSizer is used extensively by NASA for design and trades

- Employs FEA (NASTRAN/Abaqus) loads model to obtain panel and beam level loading

- Uses closed-form panel homogenization and localization methods to obtain local and ply stresses

- Evaluates design vs. a multitude of specific failure criteria/theories

- Panel buckling, FS wrinkling, dimpling, core crushing, core shear crimping, 15 strength

- Considers load cases simultaneously

- Sizes all geometry of panels/beams and selects material for min. weight

- Updates materials in FEA model to reflect new design

- Iterations between HyperSizer optimization and FEA conducted to obtain converged design

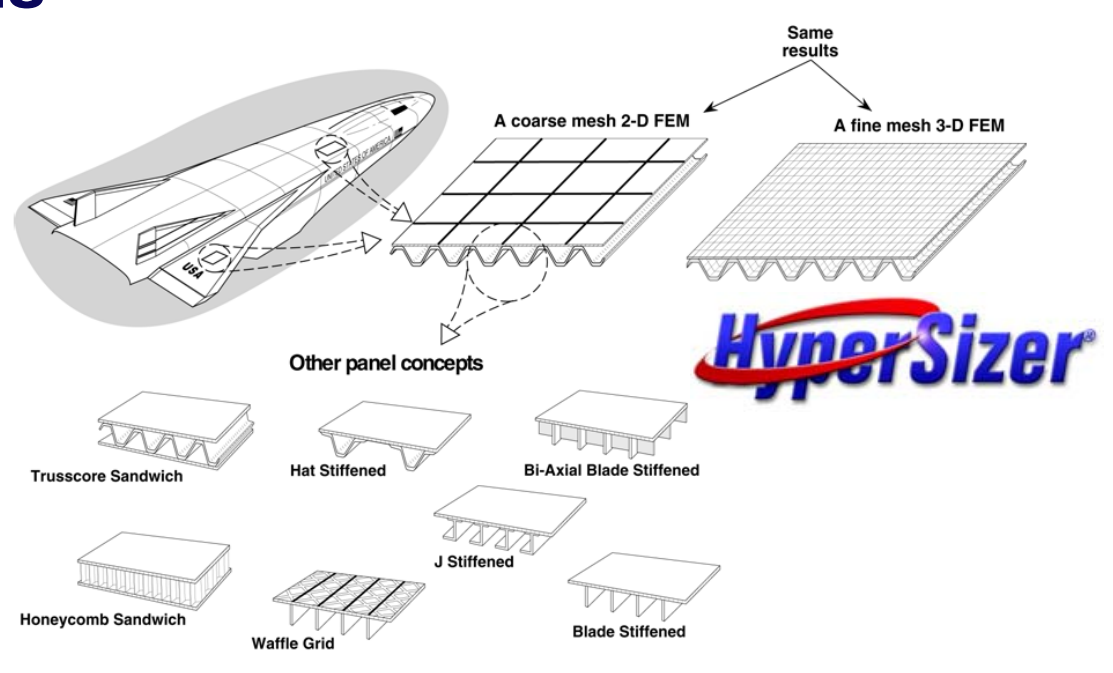

New - HyperFEA automated FEA iterations

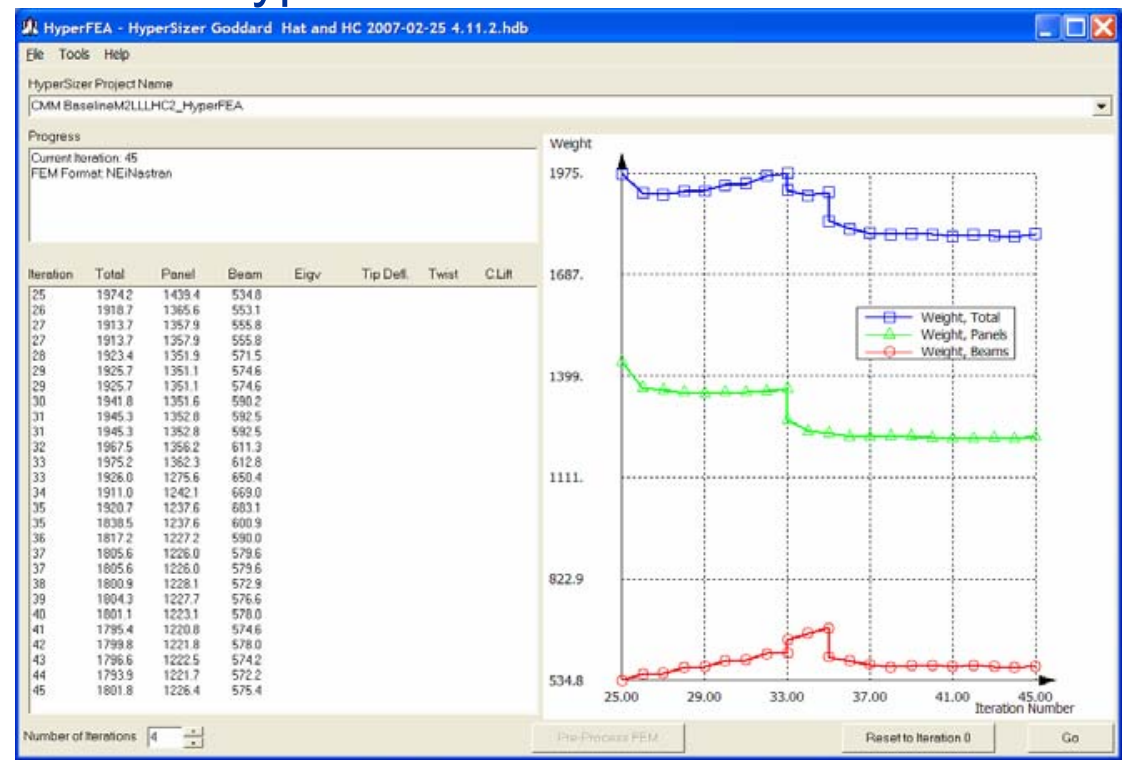




\section{Previously, through-thickness shear loading was not considered for stiffened panels and unstiffened laminates}

\section{Structural FEA}

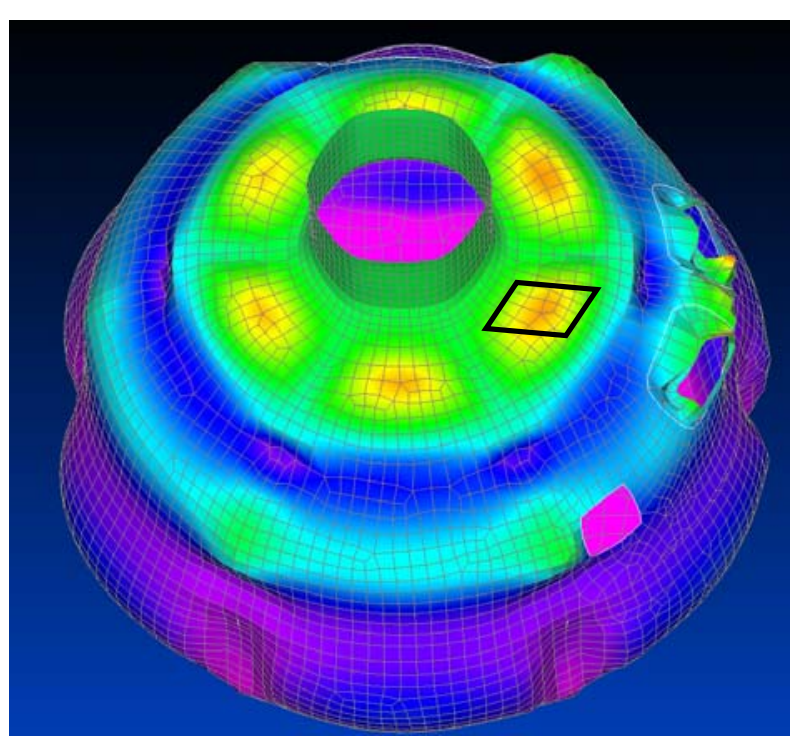

\section{Candidate Panel Concepts}
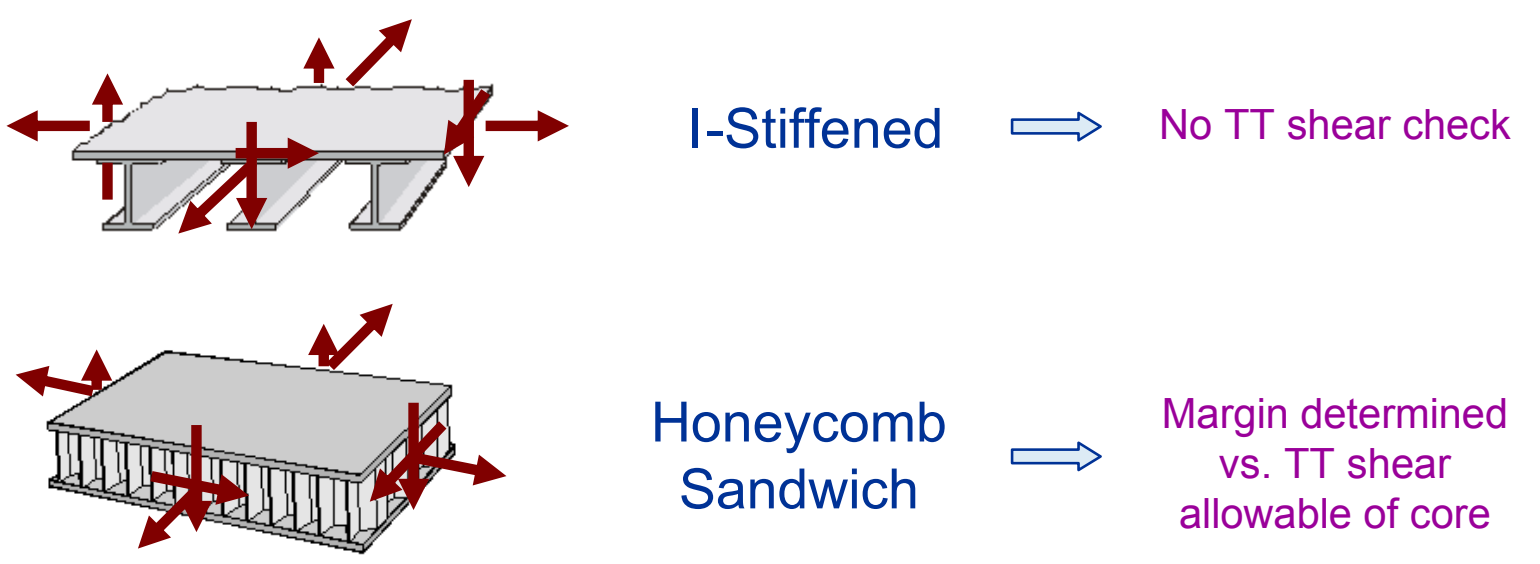

Honeycomb

Sandwich
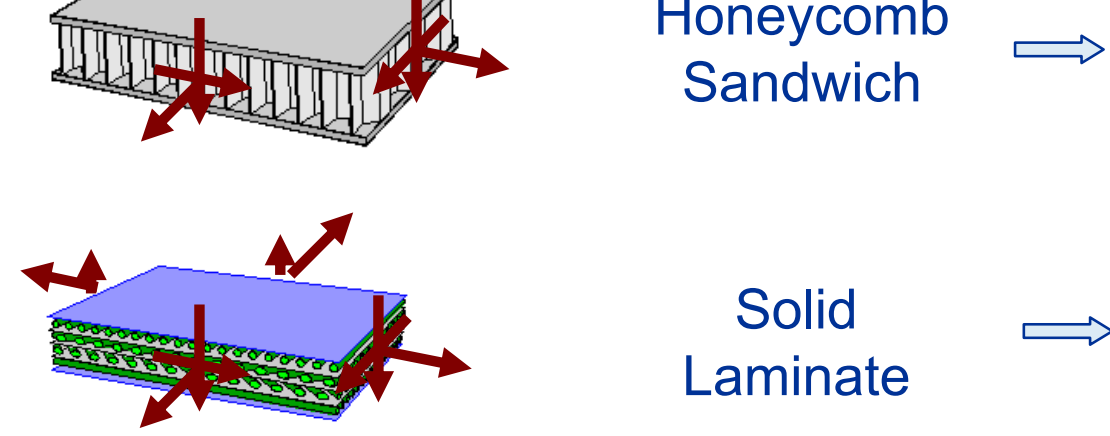

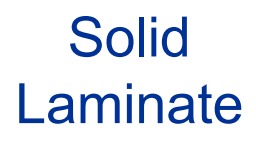

- In-plane loads $\left(N_{x}, N_{y}, N_{x y}, M_{x}, M_{y}, M_{x y}\right)$ handled consistently

- Panel homogenization methods and CLT $\rightarrow$ ply-level fields for margin calculation

- Through-thickness shear loads $\left(Q_{x}, Q_{y}\right)$ only considered for sandwich panel core

- Cannot determine ply-level margins or perform concept trades

- Shortcoming identified by NASA - collaborated with Collier R\&D to overcome 


\section{A method was needed to determine ply-level shear stresses given the panel-level shear loads}

\section{Desired Characteristics}

- Efficient

- Will be called thousands of times by HyperSizer during optimization

- Accurate

- Integrate to the applied shear resultant

- Zero at free surfaces

- Continuous at ply interfaces

- Able to be applied without knowledge of boundary conditions

- Not a plate theory solution to a boundary value problem

- Boundary conditions not available

- Looking for something analogous to CLT

- Given laminate layup/ply properties and loads (N, M)

- Can calculate in-plane ply-level stresses 


\section{The proposed method is based on the concept of a composite beam subjected to bending due to shear}

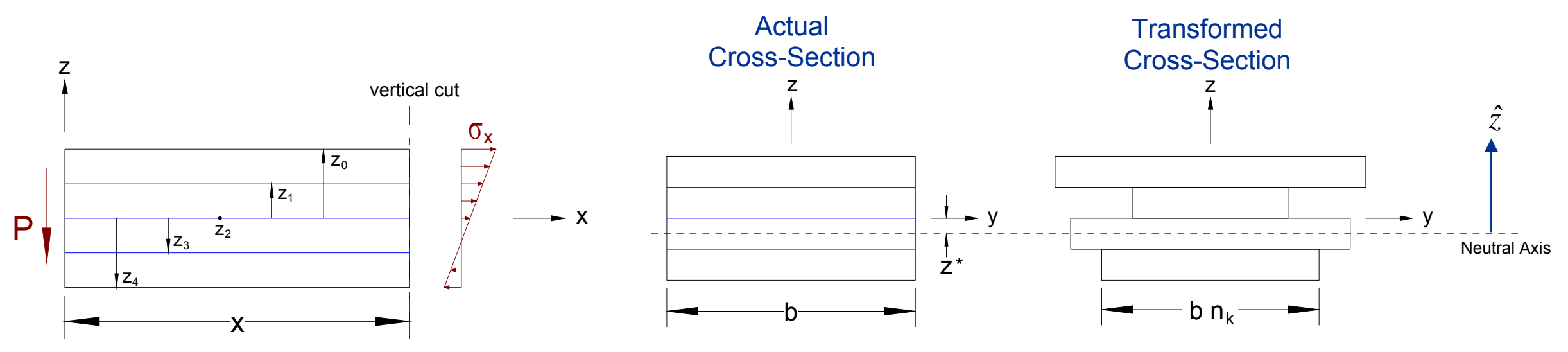

- Actual ply width (b) replaced by transformed ply width $\left(\mathrm{b}_{\mathrm{k}}\right), \quad n_{k}=\frac{E_{x}^{k}}{\bar{E}_{x}}$

- Scales the plies by axial moduli ratios

- Employ plane strain moduli: $E_{x}^{k} \rightarrow E_{x}^{k} /\left[1-v_{x y}^{k} v_{y x}^{k}\right]$

- Neutral axis given by:

$$
z^{*}=\frac{\sum_{k=1}^{N} \frac{1}{2}\left(z_{k}+z_{k-1}\right) A_{k}}{\sum_{k=1}^{N} A_{k}}=\frac{\sum_{k=1}^{N} \frac{1}{2}\left(z_{k}+z_{k-1}\right) t_{k} n_{k}}{\sum_{k=1}^{N} t_{k} n_{k}} \longrightarrow \begin{aligned}
& \hat{z}=z-z^{*} \\
& \begin{array}{l}
\text { Distance of point from } \\
\text { neutral axis }
\end{array}
\end{aligned}
$$




\section{Beam theory and equilibrium are applied}

- Beam theory axial stress given by, $\sigma_{x}=-\frac{M \hat{z}}{I}=\frac{P x \hat{z}}{I}$

- Consider horizontal cut at $\hat{z}=\hat{z}_{c} \quad z$

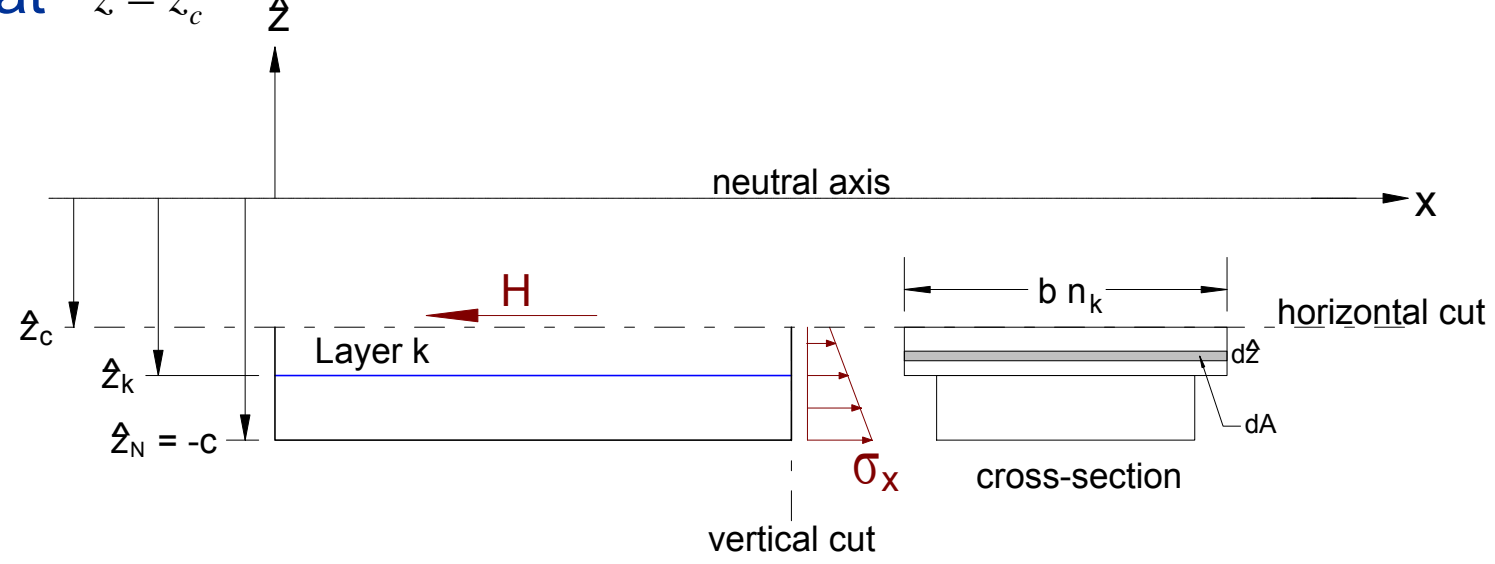

- Equilibrium dictates, $-H+\int \sigma_{x} d A=0 \longrightarrow H=\frac{P x}{I} \int_{i_{\mathrm{N}}}^{\hat{i}_{\mathrm{N}}} \hat{z} \mathrm{~d} A$

- Substituting,

$$
d A=b n_{k} d \hat{z} \longrightarrow H=\frac{P x}{I} \int_{\hat{z}_{N}}^{\hat{z}_{c}} b n_{k} \hat{z} d \hat{z}
$$

- Integral denoted by Q',

$Q^{\prime}(k, \hat{z})=\int_{\hat{z}_{N}}^{\hat{z}_{c}} b n_{k} \hat{z} d \hat{z}=\int_{\hat{z}_{k}}^{\hat{z}_{c}} b n_{k} \hat{z} d \hat{z}+\int_{\hat{z}_{k+1}}^{\hat{z}_{k}} b n_{k+1} \hat{z} d \hat{z}+\ldots+\int_{\hat{z}_{N}}^{\hat{z}_{N-1}} b n_{N} \hat{z} d \hat{z} \quad Q^{\prime}(k, \hat{z})=\frac{b n_{k}}{2}\left(\hat{z}_{c}^{2}-\hat{z}_{k}^{2}\right)+\frac{1}{2} \sum_{m=k+1}^{N} b n_{m}\left(\hat{z}_{m-1}^{2}-\hat{z}_{m}^{2}\right)$

- Piece-wise parabolic and continuous at interfaces through the thickness 


\section{Shear stress distribution is determined from shear force $(\mathrm{H})$ distribution}

- Shear force distribution, $H=\frac{P X}{I} Q^{\prime}(k, \hat{z})$

- Shear stress distribution, $\tau=-\frac{H}{x b}=-\frac{P}{I b} Q^{\prime}(k, \hat{z})$

- Shear resultant, $Q=P / b$

- Final form, $\tau(k, \hat{z})=-\frac{Q}{I} Q^{\prime}(k, \hat{z})$

- With, $\quad I=\sum_{k=1}^{N}\left[\frac{1}{12} b n_{k} t_{k}^{3}+b n_{k} t_{k}\left(\frac{\hat{z}_{k}+\hat{z}_{k-1}}{2}\right)^{2}\right]$

- Applicable to $\tau_{x z}$ and $\tau_{y z}$ by switching $x$ and $y$ coordinates

- No coupling between $\tau_{x z}$ and $\tau_{y z}$

- Can superimpose effects of $Q_{x}$ and $Q_{y}$

- Assumes plate is thin - dominated by bending 


\section{SSS shear stress fields compared to other theories for several layups}

- Compare to Higher-Order Theory for Functionally Graded Materials $\left(\right.$ HOTFGM) ${ }^{1}$ plate solution

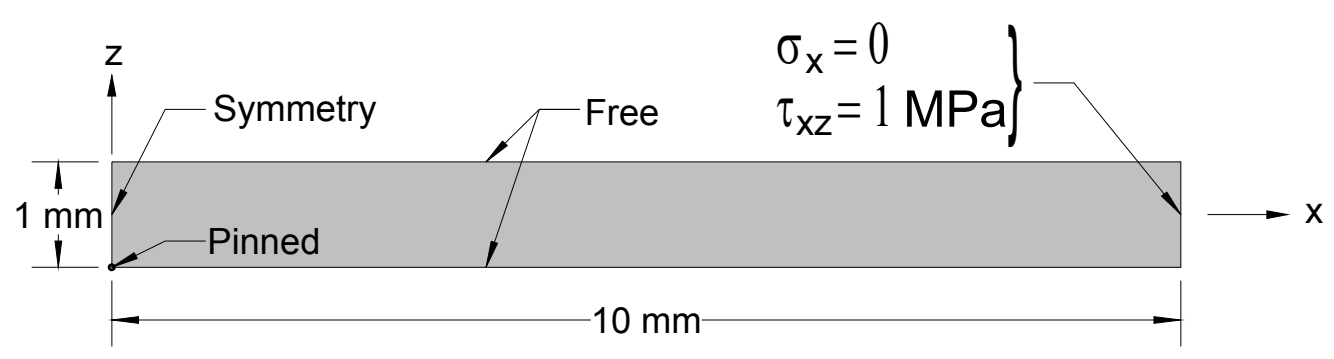

- Compare to HyperSizer Joints ${ }^{2}$ bonded laminate in cylindrical bending solution

${ }^{1}$ Aboudi, J., Pindera, M.-J., and Arnold, S.M., "Higher-Order Theory for Functionally Graded Materials," Composites Part B, Vol. 30, 1999, pp. $777-832$.

${ }^{2}$ Zhang, J., Bednarcyk, B.A., Collier, C.S., Yarrington, P.W., Bansal, Y., and Pindera, M.-J., "Analysis Tools for Adhesively Bonded Composite Joints Part 2: Unified Analytical Theory," AIAA Journal, Vol. 44, 2006, pp. 1709-1719. 


\section{SSS matches well for various layups with isotropic plies}
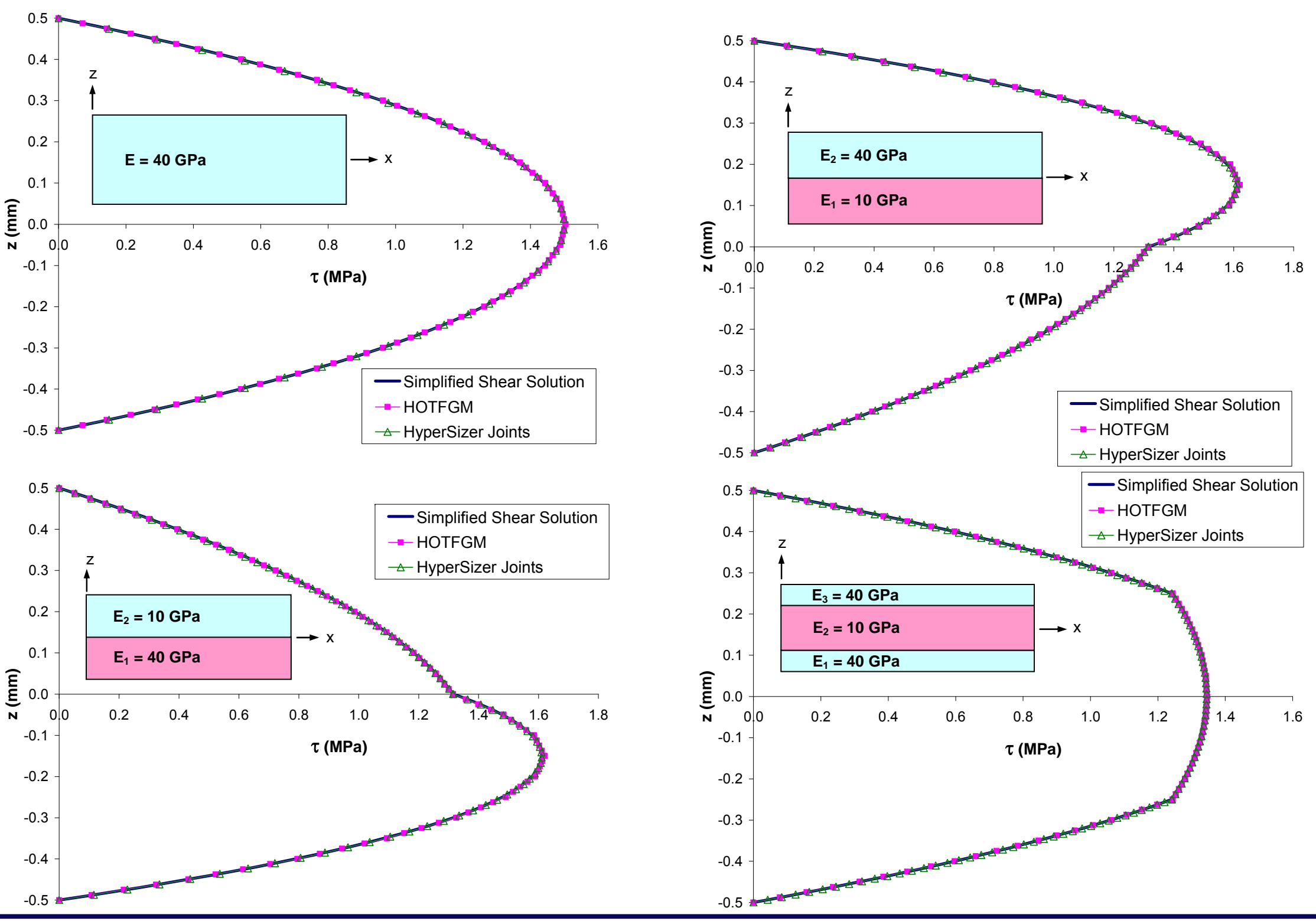


\section{SSS matches well for various layups with isotropic plies}

Addition of Poisson Mismatch
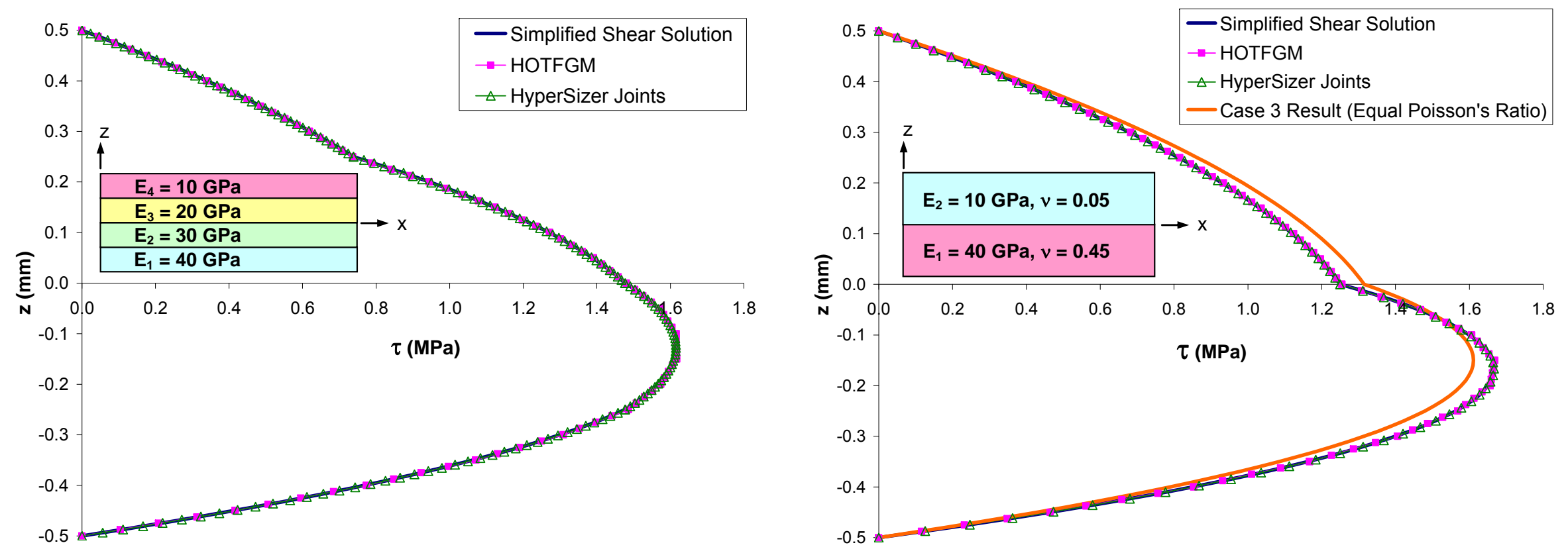


\section{Comparison to a true plate theory shows the ability of SSS to approximate the shear distribution without knowledge of BCs}

- Compare to Williams'3 multilength scale plate theory

- Solves plate boundary value problem

- Subjected to sinusoidal pressure loading

- Shown to correspond to Pagano's ${ }^{4}$ exact solution

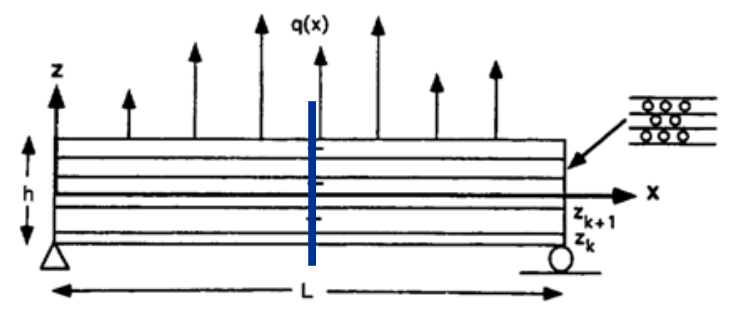

- SSS applied $Q_{x}$ determined by integrating Williams' theory $\tau_{x z}$ distribution from a location in the plate $\left(Q_{x}=0.32 \mathrm{~N} / \mathrm{mm}\right)$

- Material properties:

\begin{tabular}{|l|c|c|c|c|c|c|}
\hline Ply Angle $\left(^{\mathbf{0}}\right)$ & $\mathbf{- 3 0}$ & $\mathbf{0}$ & $\mathbf{3 0}$ & $\mathbf{4 5}$ & $\mathbf{6 0}$ & $\mathbf{9 0}$ \\
\hline $\mathbf{E}_{\mathrm{x}}(\mathbf{G P a})$ & 2.192 & 25 & 2.192 & 1.325 & 1.068 & 1 \\
\hline $\mathrm{E}_{\mathrm{y}}(\mathbf{G P a})$ & 1.068 & 1 & 1.068 & 1.325 & 2.192 & 25 \\
\hline$v_{\mathrm{xy}}$ & 0.4082 & 0.25 & 0.4082 & 0.3245 & 0.1989 & 0.01 \\
\hline
\end{tabular}

- Layups considered:

$\left.-\left[0^{\circ} / 90^{\circ} / 0^{\circ} / 90^{\circ} / 0^{\circ}\right],\left[0^{\circ} / 90^{\circ} / 45^{\circ} / 90^{\circ} / 0^{\circ}\right],\left[-30 \% / 90^{\circ} / 45^{\circ} / 60^{\circ} / 30^{\circ}\right]\right\}$ asymmetric

-Ply thicknesses: $[0.2,0.4,0.2,0.1,0.1] \mathrm{mm}$

${ }^{3}$ Williams, T.O., "A Generalized Multilength Scale Nonlinear Composite Plate Theory with Delamination,” International Journal of Solids and Structures, Vol. 36, 1999, pp. 3015-3050.

${ }^{4}$ Pagano, N., "Exact Solutions for Composite Laminates in Cylindrical Bending," Journal of Composite Materials, Vol. 3, 1969, pp. 398-411 


\section{SSS is approximate compared to true plate theory, and presence of anisotropic plies causes some deviation}

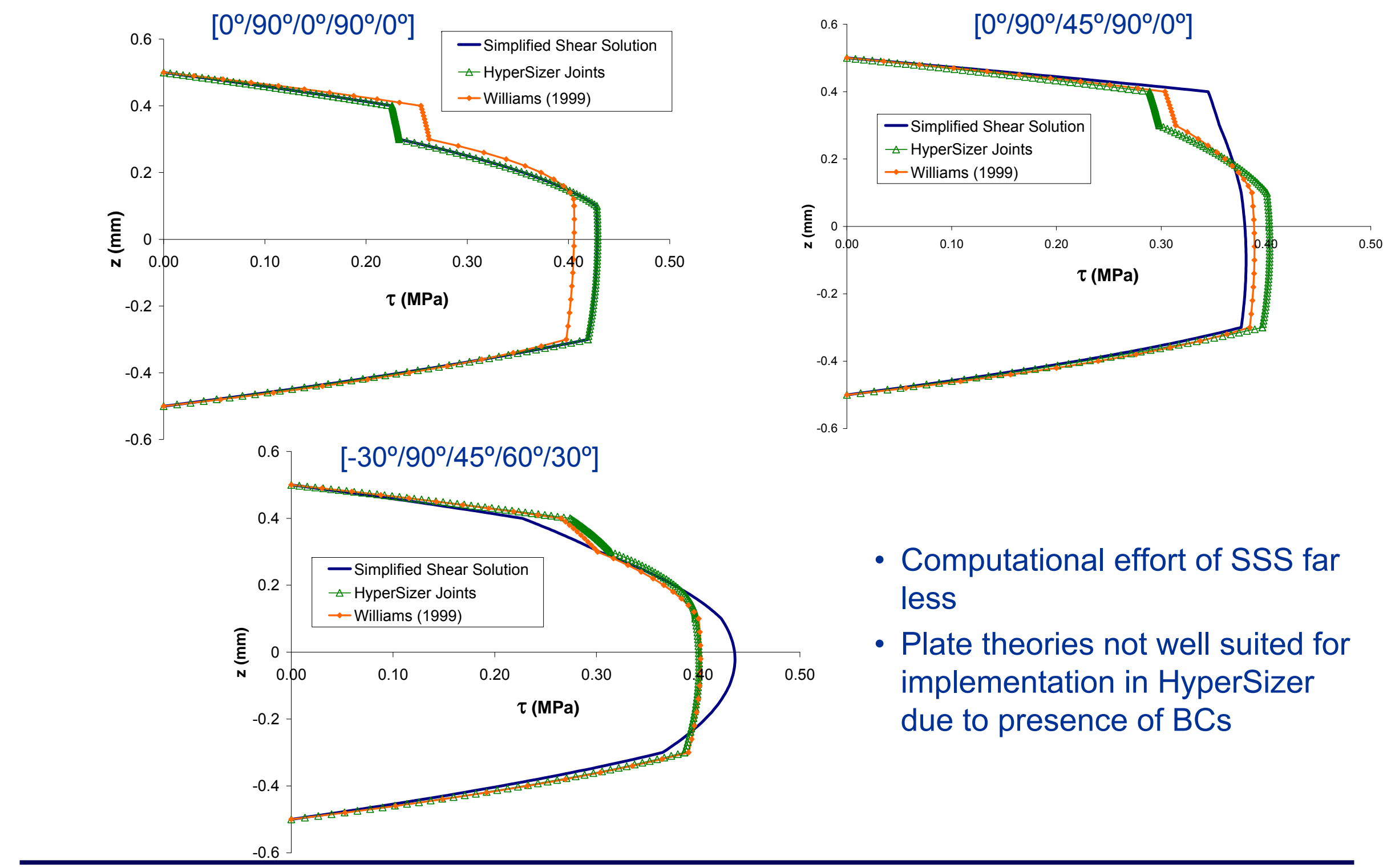




\section{Stiffened panel design in HyperSizer is accomplished by considering the ply margins due to TT shear}

- Ply-level $\tau_{x z}$ and $\tau_{y z}$ are transformed to ply coordinates:

$$
\left\{\begin{array}{l}
\tau_{13} \\
\tau_{23}
\end{array}\right\}=\left[\begin{array}{cc}
\cos \theta & \sin \theta \\
-\sin \theta & \cos \theta
\end{array}\right]\left\{\begin{array}{c}
\tau_{x z} \\
\tau_{y z}
\end{array}\right\}
$$

- TT shear interaction equation considered as failure criterion:

$$
\left(\frac{\tau_{13}}{F s u_{13}}\right)^{2}+\left(\frac{\tau_{23}}{F s u_{23}}\right)^{2}=1
$$

- Margin of safety given by: $M S=\frac{1}{\sqrt{\left(\frac{\tau_{13}}{F s u_{13}}\right)^{2}+\left(\frac{\tau_{23}}{F s u_{23}}\right)^{2}}}-1$

- MS = 0 at failure, positive margin good, negative margin indicates failure

- Optimum design is lightest panel that provides all positive margins

- HyperSizer checks a multitude of margins (e.g., Panel buckling, FS wrinkling, dimpling, core crushing, core shear crimping, 15 strength) 


\section{Determination of TT shear margins in a unstiffened laminate}

- Consider $\left[45 \%-45 \% 0^{\circ} / 90 \% \% \% 0 \% / 45 \%-45 \% 0^{\circ}\right]_{\mathrm{S}}$ laminate

- Ply thickness $=0.005$ in.

- Subjected to $Q_{x}=Q_{y}=200 \mathrm{lb} / \mathrm{in}$

- Graphite/Epoxy ply material properties:

\begin{tabular}{|c|c|c|c|c|}
\hline $\mathbf{E}_{\mathbf{1}} \mathbf{( M s i )}$ & $\mathbf{E}_{\mathbf{2}}(\mathbf{M s i})$ & $\mathbf{v}_{\mathbf{1 2}}$ & $\mathbf{F s u}_{\mathbf{1 3}}(\mathbf{k s i})$ & $\mathbf{F s u}_{\mathbf{2 3}}(\mathbf{k s i})$ \\
\hline 23.35 & 1.65 & 0.32 & 14.8 & 5.32 \\
\hline
\end{tabular}

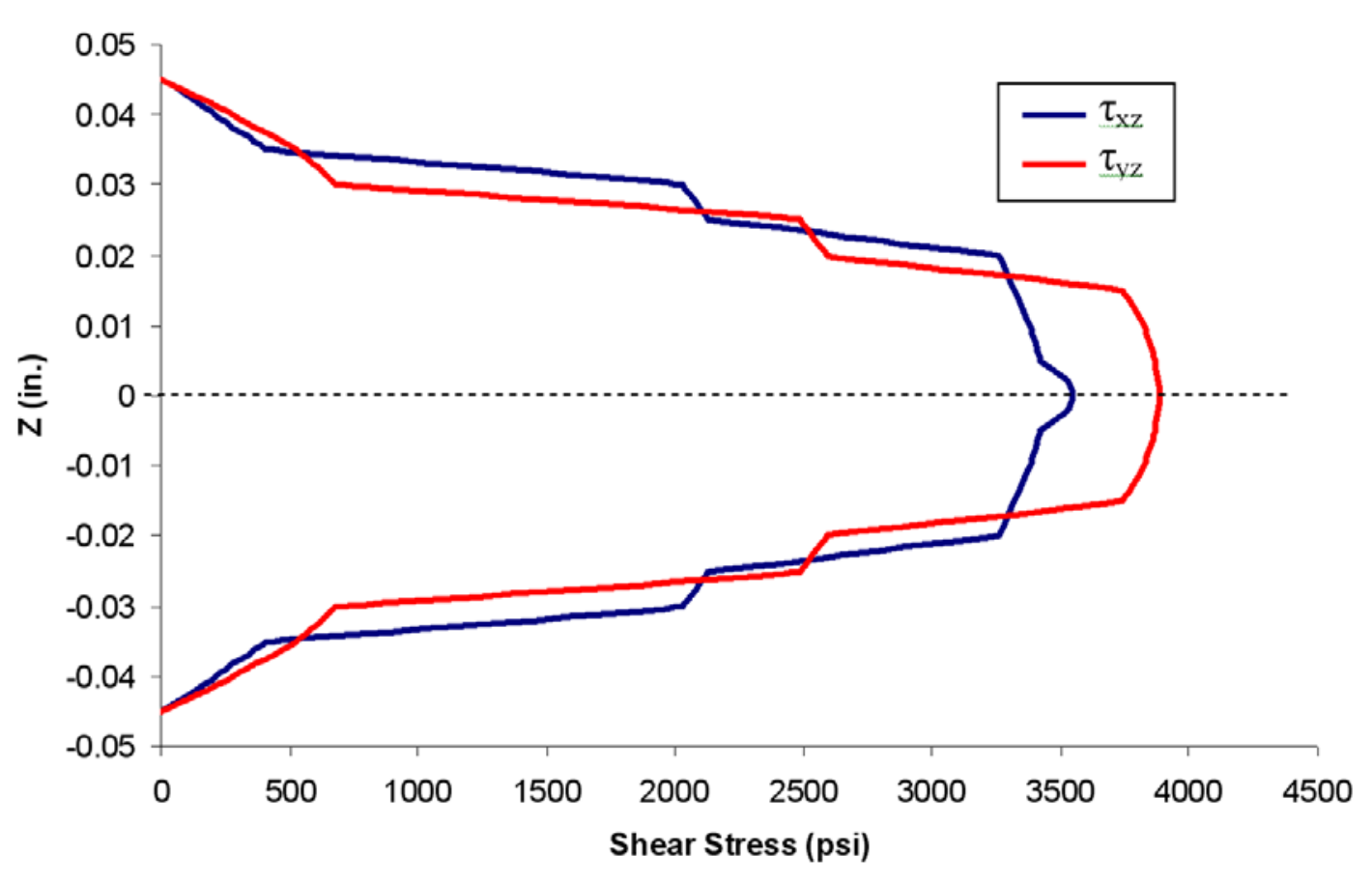




\section{Determination of TT shear margins in an unstiffened}

\section{laminate}
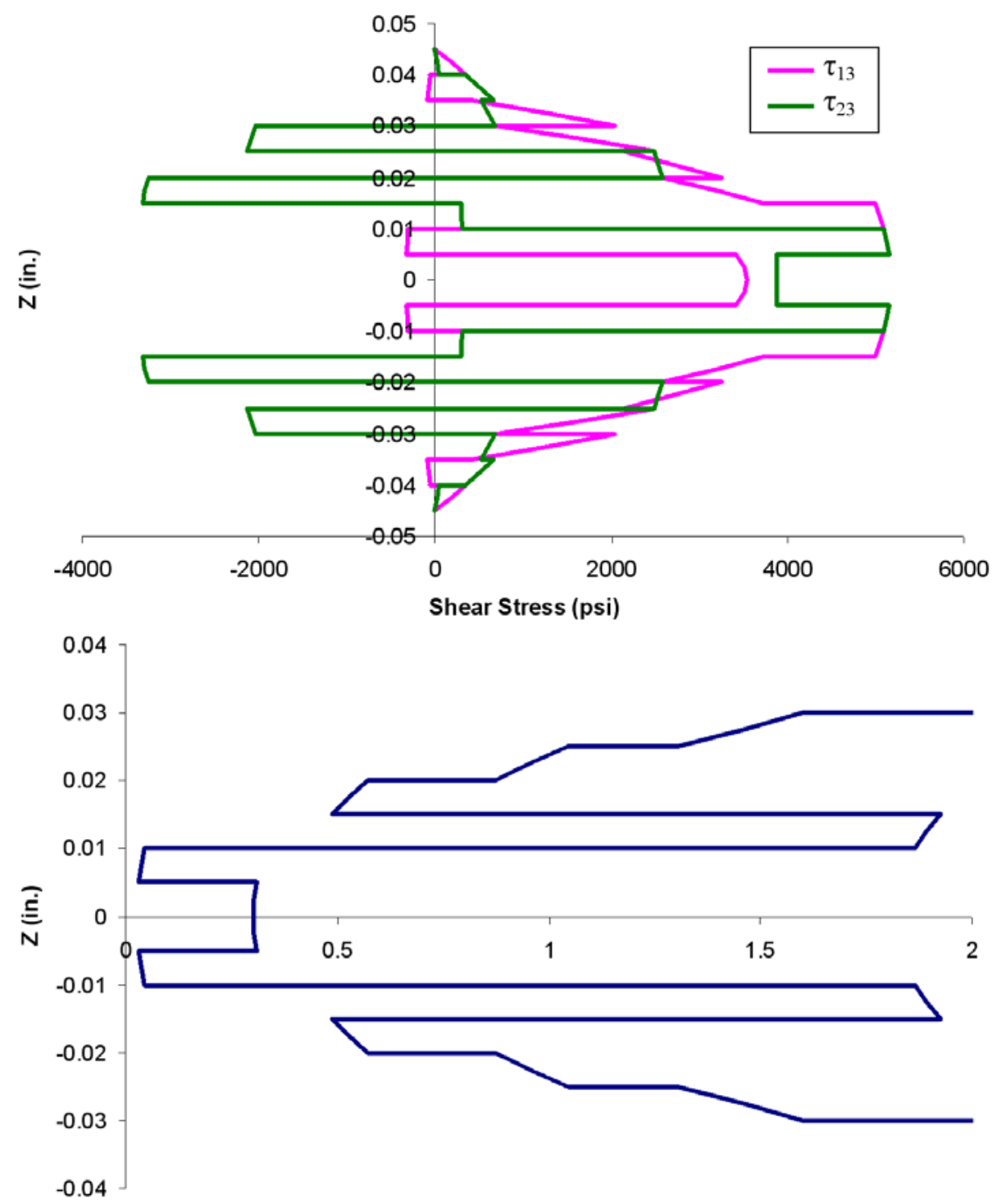

Margin positive throughout design acceptable 


\section{Determination of TT shear margins in a honeycomb sandwich panel}

- Facesheet laminates same as previous unstiffened laminate

- Hexcell HRH 10 (Nomex/Phenolic) honeycomb core thickness = $1.5 \mathrm{in}$.

- Subjected to $Q_{x}=Q_{y}=1000 \mathrm{lb} / \mathrm{in}$

- Core material properties:

\begin{tabular}{|c|c|c|}
\hline $\mathbf{E}_{\mathrm{x}}=\mathbf{E}_{\mathrm{y}}$ (psi) & Fsu $_{\mathrm{xz}}$ (ksi) & Fsu $_{\mathrm{yz}}$ (ksi) \\
\hline 0.0001 & 0.225 & 0.11 \\
\hline
\end{tabular}

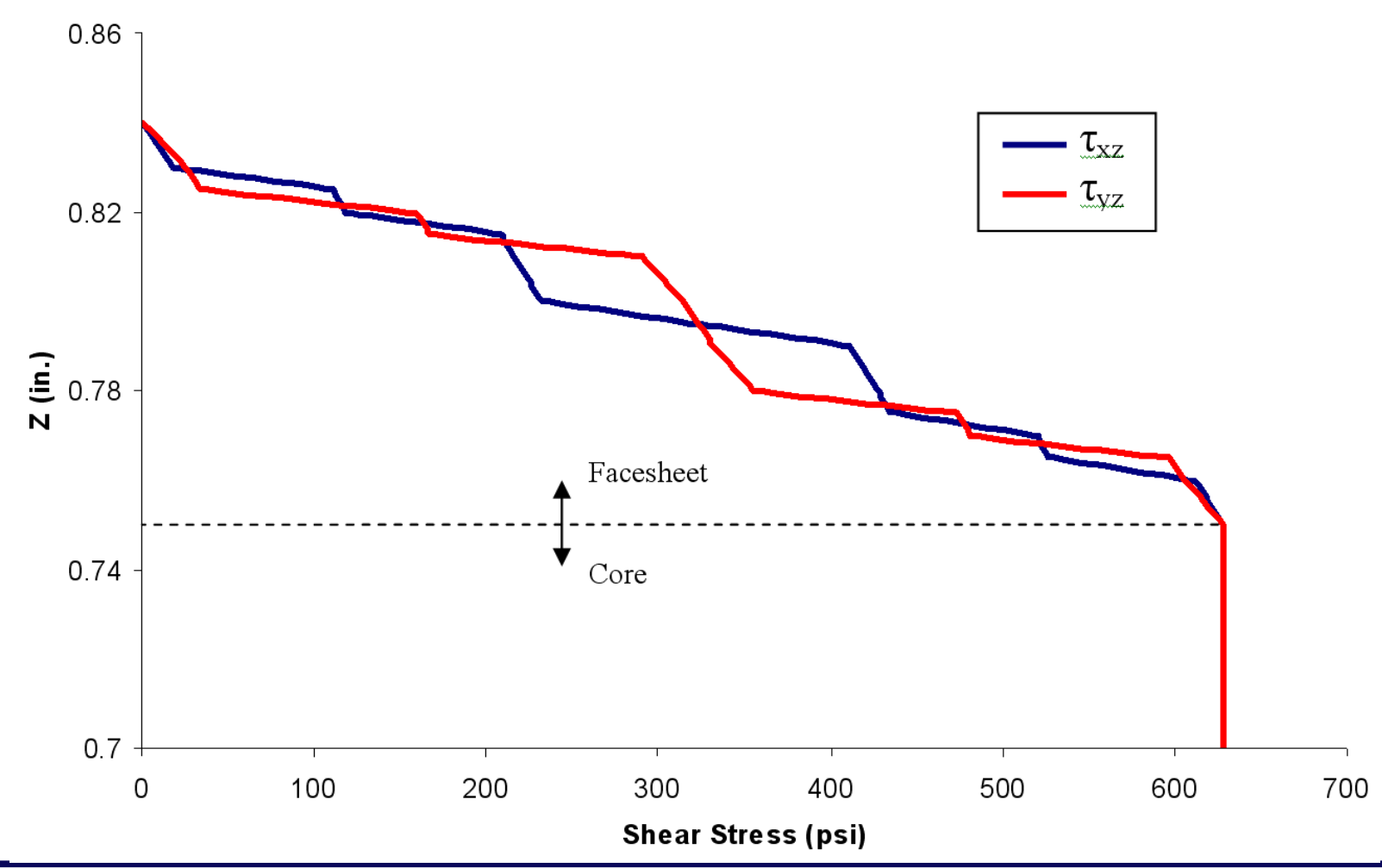




\section{Determination of TT shear margins in a honeycomb} sandwich panel

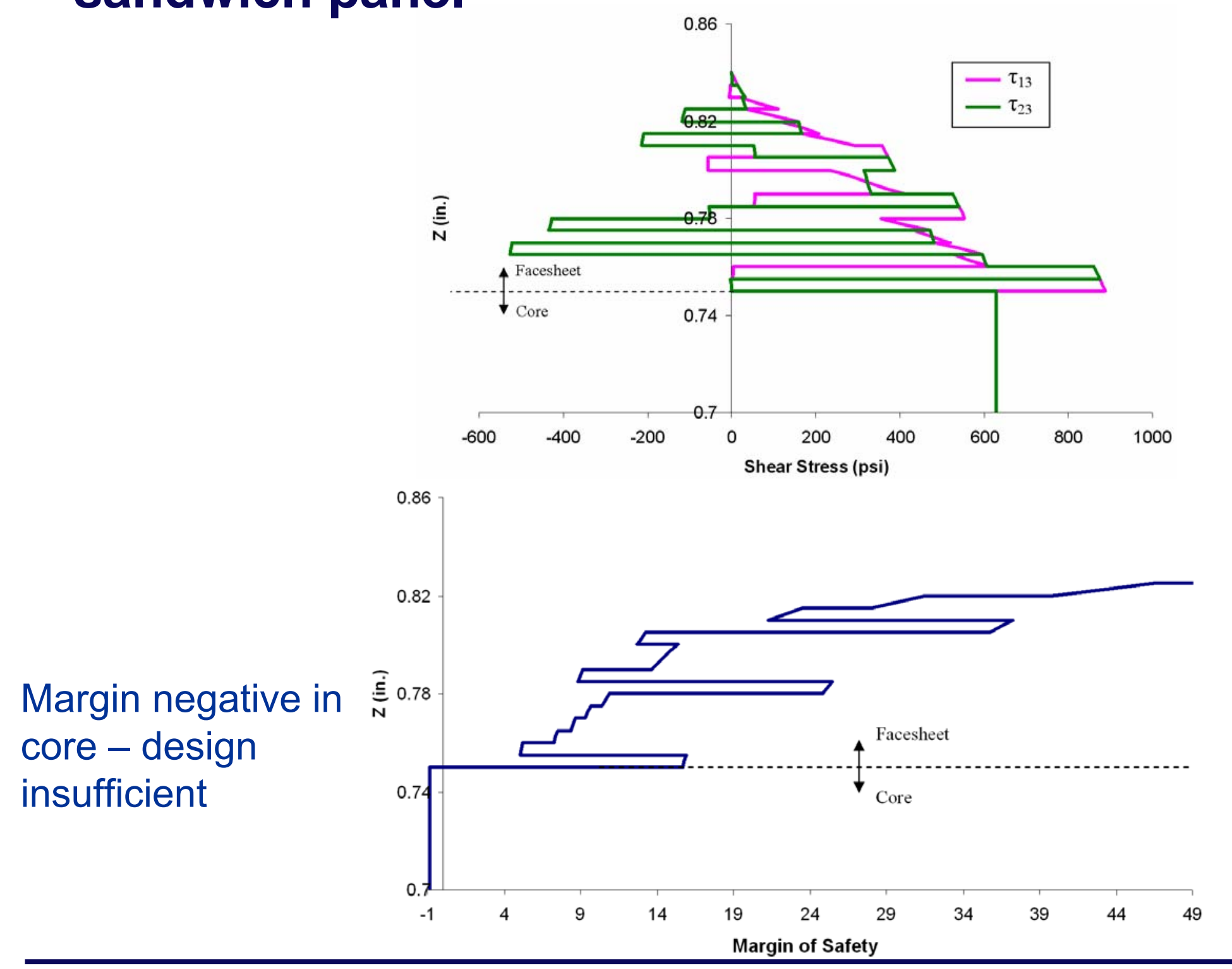




\section{Determination of TT shear margins in an I-stiffened panel}

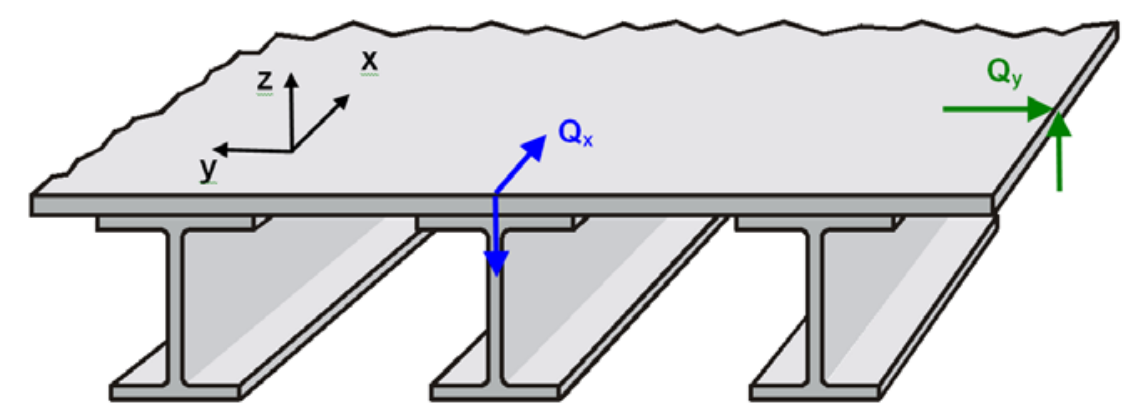

- For $Q_{x}$, stiffener aligned with shear force, (smeared) stiffener webs contribute

- For $Q_{y}$, stiffener webs do not contribute - shear force applied to facesheet only

- Same facesheet layup, [45/-45/0/90/0/90/45/-45/0 $]_{\text {S }}$

- Ply thicknesses of 0.005 in.

- Upper flange and web of the I-stiffeners are [0/90/45/-45]

- Ply thickness of 0.00375 in.

- Lower flange layup is [0/90/45/-45/0/0 $]_{\mathrm{s}}$

- Ply thickness of $[0.005 / 0.005 / 0.005 / 0.005 / 0.00375 / 0.00375]_{S}$ in.

- Applied shear loading is $Q_{x}=Q_{y}=200 \mathrm{lb} / \mathrm{in}$. 


\section{Determination of TT shear margins in an I-stiffened panel}
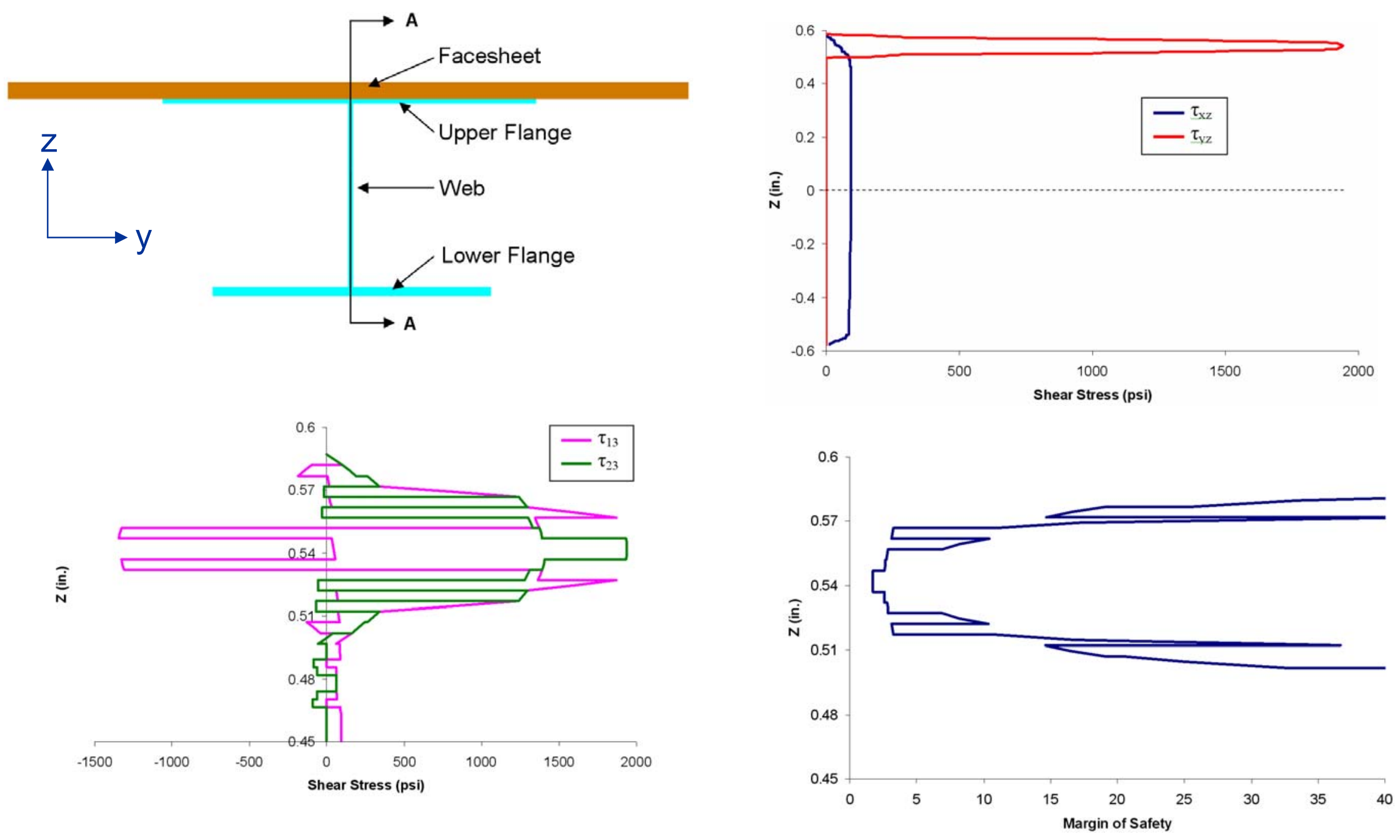

Margin $>1$ throughout - design overly conservative 


\section{Design of unstiffened laminates in a pressure shell structure considering TT shear}

- 14 unstiffened laminate panels within a spacecraft pressure shell:

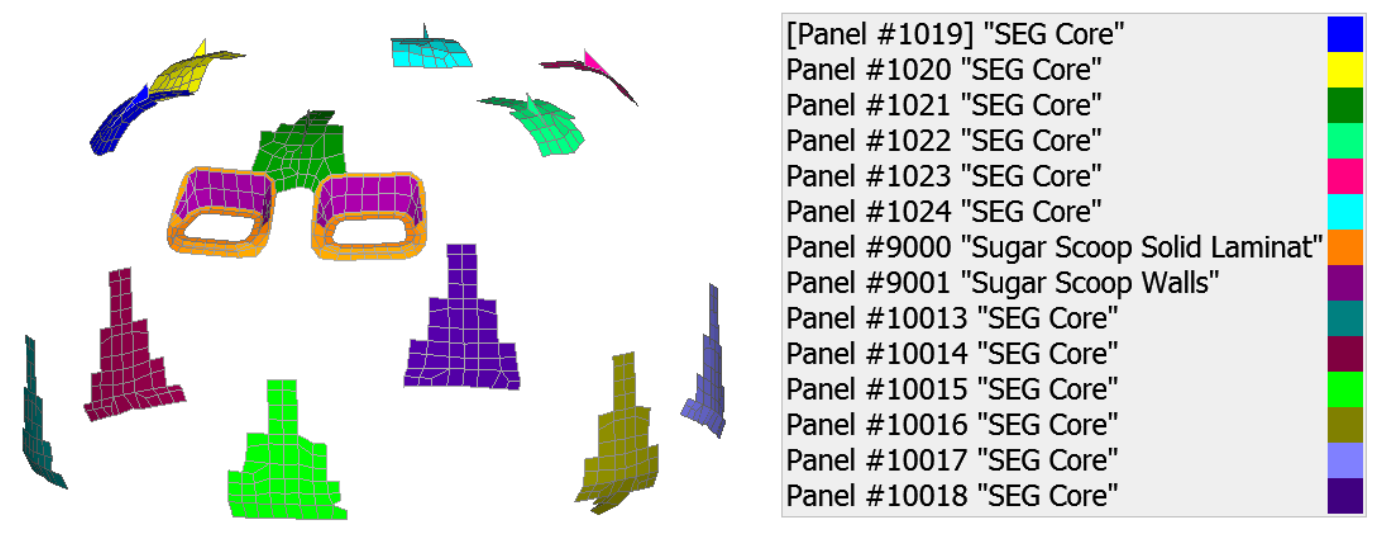

- Woven graphite/epoxy ply material properties:

\begin{tabular}{|c|c|c|c|c|c|c|c|c|}
\hline $\begin{array}{c}\mathrm{E}_{1} \\
(\mathrm{Msi})\end{array}$ & $\begin{array}{c}\mathrm{E}_{2} \\
(\mathrm{Msi})\end{array}$ & $v_{12}$ & $\begin{array}{c}\mathrm{G}_{12} \\
(\mathrm{Msi})\end{array}$ & $\begin{array}{c}\mathrm{Ftu}_{1} \\
(\mathrm{ksi})\end{array}$ & $\begin{array}{c}\mathrm{Ftu}_{2} \\
(\mathrm{ksi})\end{array}$ & $\begin{array}{c}\mathrm{Fsu}_{12} \\
(\mathrm{ksi})\end{array}$ & $\begin{array}{c}\mathrm{Fsu}_{13} \\
(\mathrm{ksi})\end{array}$ & $\begin{array}{c}\mathrm{Fsu}_{23} \\
(\mathrm{ksi})\end{array}$ \\
\hline 10.5 & 10.5 & 0.036 & 0.84 & 59 & 59 & 13 & 6.9 & 6.9 \\
\hline
\end{tabular}

- The ply thickness is $0.008 \mathrm{in}$.

- HyperSizer is used to determine the number of plies (and thus total thickness) needed for each composite panel

- Candidate laminates consisting of only $0^{\circ}$ and $45^{\circ}$ plies in a symmetric layup were considered

- 45 load cases (pressure, abort, ascent, reentry, chute loads, landing, etc.) 


\section{Design of unstiffened laminates in a pressure shell structure considering TT shear}

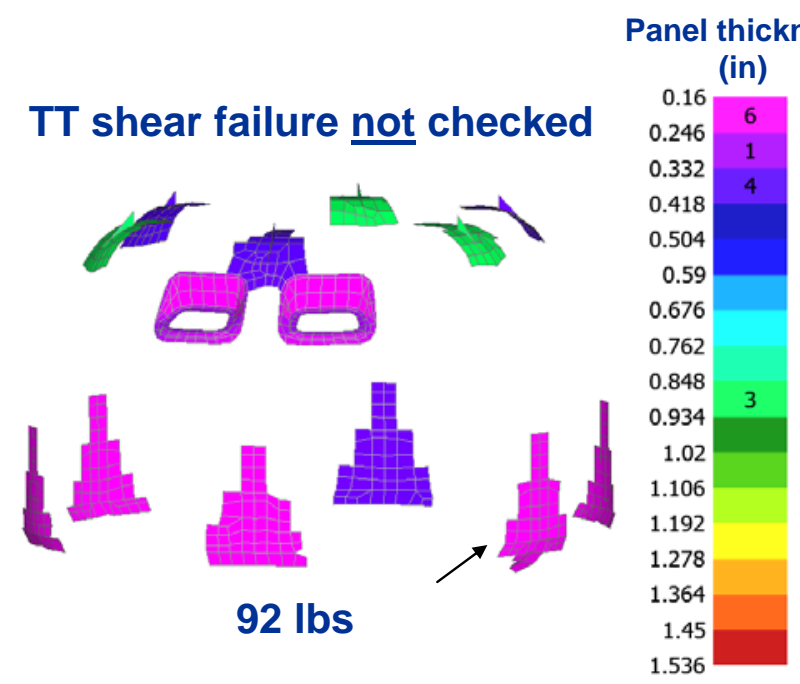

TT shear distribution in panel 10016
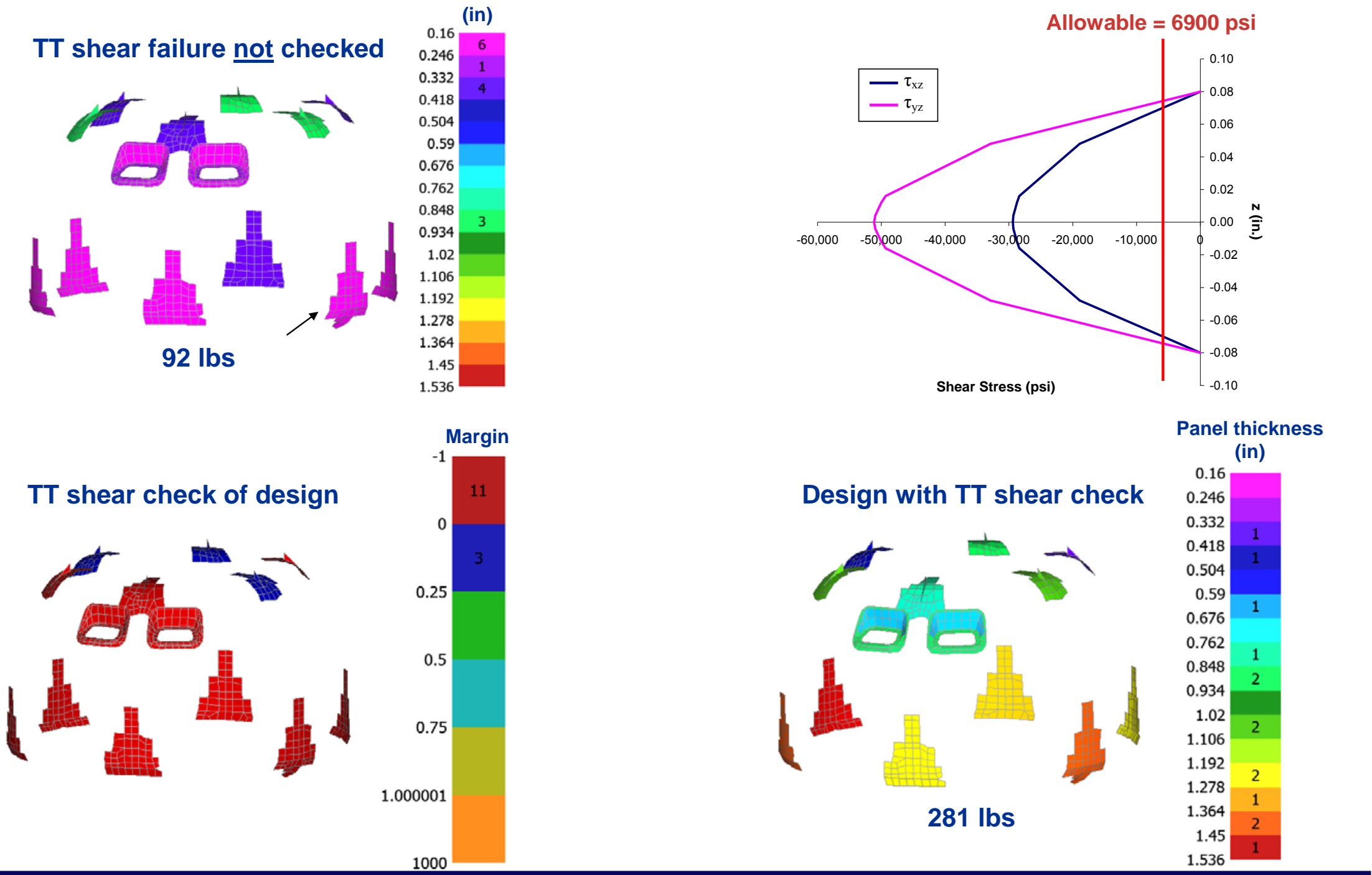


\section{Conclusions}

- A simplified method based on laminated beam theory has been presented for determination of the shear stress distribution in laminated plates and panels caused by applied shear force resultants

- The method is straightforward and efficient

- Does not require the solution of elasticity equations in the presence of the corresponding boundary conditions

- Provides an estimate of the shear stress distribution with no knowledge of the details of the structure using only panel cross-section geometry, material properties, and the applied load

- Analogous to in-plane predictions of CLT

- The predicted shear stress distribution for laminates are shown to be in excellent agreement with HOTFGM and HyperSizer Joints for isotropic plies

- For anisotropic plies, the agreement between the simplified shear solution, HyperSizer Joints, and plate theory is satisfactory given the simplicity and efficiency SSS

- The method has been applied to predict the biaxial shear distributions in unstiffened laminates, a honeycomb sandwich panel, and I-stiffened panel

- The shear stress distributions in the local ply coordinates are obtained by the relevant transformations, enabling determination of the margins of safety of these composite structures

- Limitations include:

- Predictions will be less accurate as laminate becomes thick and is less dominated by bending

- Method predicts zero shear stress throughout laminate if applied shear load is zero

- No interaction between $\tau_{x z}$ and $\tau_{y z}$ - determined independently and superimposed 